\title{
STRESS MANAGEMENT (HOW TO TURN STRESS INTO HIGH PRODUCTIVITY)
}

\author{
Fahrul Riza $^{1)}$, Lanang Diayudha $^{2)}$, Andreas Wijaya $^{3)}$, Tannia $^{4)}$, Rudy Santosa Sudirga $^{\text {(5) }}$ \\ 1), 2), 3), 4), 5) Program Studi Manajemen, Universitas Bunda Mulia
}

Diterima 23 Desember 2020 / Disetujui 5 Januari 2021

\begin{abstract}
Stress Management (How To Turn Stress Into High Productivity). If you are living with high level of stress, you are putting your entire well-being at risk. It narrows your ability to think clearly, function effectively, and enjoy life. It may seem that there is nothing you can do about stress. Effective stress management help you break the hold stress has on your life, so you can be happier, healthier, and more productive. The ultimate goal is a balanced life, with time for work, relationships, rileksation and fun, and the resilience to hold up under pressure and meet challenges head on. Stress management starts with identifying the sources of stress in your life, this isn't as straightforward as it sounds. While it's easy to identify major stressors such as changing jobs, moving, or going through a divorce, pinpointing the sources of chronic stress can be more complicated. It's all too easy to overlook how your own thoughts, feelings, and behaviors contribute to your everyday stress levels.A stress journal can help you identify the regular stressors in your life and the way you deal with them. Each time you feel stressed, keep track of it in your journal or use a stress tracker on your phone. The following stress management tips in this article can help you to overcome the stress in your life.
\end{abstract}

Keywords: Stess, Management, Turn Into, High Productivity.

\begin{abstract}
ABSTRAK
Manajemen Stres (Bagaimana Mengubah Stres Menjadi Produktivitas Tinggi). Jika anda hidup dengan tingkat stres yang tinggi, anda akan mempertaruhkan seluruh kesejahteraan anda. Ini mempersempit kemampuan anda untuk berpikir jernih, berfungsi secara efektif, dan menikmati hidup ini. Tampaknya tidak ada yang dapat Anda lakukan untuk mengatasi stres. Manajemen stres yang efektif dapat membantu anda menghentikan tekanan pada hidup anda, sehingga anda bisa menjadi lebih bahagia, lebih sehat, dan lebih produktif. Tujuan utamanya adalah kehidupan yang seimbang, dengan memperhatikan waktu untuk bekerja secara seimbang, hubungan antar sesama, kegembiraan dan kesenangan, dan ketahanan untuk bertahan di bawah tekanan dan menghadapi tantangan langsung. Manajemen stres dimulai dengan mengidentifikasi sumber stres dalam hidup anda dan ini tidak sesederhana kedengarannya. Meskipun mudah untuk mengidentifikasi pemicu stres utama seperti berganti pekerjaan, pindah, atau mengalami perceraian, menemukan sumber stres kronis bisa lebih rumit. Sangat mudah untuk mengabaikan bagaimana pikiran, perasaan, dan perilaku anda berkontribusi pada tingkat stres anda seharihari. Jurnal stres dapat membantu anda mengidentifikasi penyebab stres biasa dalam hidup anda dan cara anda menghadapinya. Setiap kali anda merasa stres, lihatlah tips di jurnal ini atau gunakan pelacak stres di ponsel anda. Tips manajemen stres berikut dalam artikel ini dapat membantu anda untuk mengatasi stres dalam hidup anda.
\end{abstract}

Kata Kunci: Stes, Manajemen, Mengubah Menjadi, Produktivitas Tinggi.

*Korespondensi Penulis:

E-mail: rudysudirga@yahoo.com 


\section{PENDAHULUAN}

Stres adalah respon otomatis tubuh terhadap setiap tuntutan fisik atau mental yang dibebankan kepada manusia. Stres banyak terjadi pada karyawan di sebuah perusahaan. Hal ini disebabkan karena karyawan di sebuah perusahaan diberikan target dan tanggung jawab pada kinerja karyawan tersebut, sehingga banyak karyawan yang dibebani oleh stres dalam menjalankan tugas dan pekerjaannya. Tingkatan stres dibagi menjadi 3 besar, yaitu: tingkat stres yang sedikit dapat menyebabkan kebosanan, tingkat stres yang sedang sebenarnya dapat meningkatkan kinerja dan efisiensi karyawan, tingkat stres yang tinggi dapat menyebabkan kecemasan yang tidak produktif. Pemicu stres adalah situasi, aktivitas dan hubungan yang menyebabkan trauma pada fisik, emosional atau keadaan psikologis seseorang.

Menurut Copper, C. L., and Quick, J. C. (2017), kita harus bisa mengidentifikasi sumber dari stress di dalam kehidupan anda, dan secara singkat dapat dijelaskan atau diperinci sebagai berikut: (1) apa yang membuat anda stress, (2) bagaimana perasaan anda secara fisik dan emosional, (3) apa dan bagaimana anda merespon stress tersebut, (4) apa yang harus anda kerjakan agar supaya anda merasakan keadaan yang lebih baik. Menurut Copper, C. L., and Quick, J. C. (2017), dan Saleh, M.L., Russeng, S.S., Tadjuddin, I. (2020), dan Hawari, D. (2011), yang pertama anda harus mempraktekkan 4 hal dalam stres manajemen, yaitu belajar untuk mengatakan "tidak" pada hal yang melebihi kapasitas kemampuan anda, hindarilah orang yang dapat menyebabkan anda menjadi stres atau membatasi pertemuan dengan orang tersebut, harus melakukan kontrol terhadap lingkungan seperti misalnya tidak perlu melihat berita di televisi yang membuat cemas atau menghindari kerumunan orang banyak jika kerumunan orang dapat mencemaskan diri anda, buatlah daftar pekerjaan anda dan lakukanlah pekerjaan yang penting dahulu, sedangkan yang tidak penting dan mencemaskan dapat dikurangi atau ditiadakan dan dihindari. Yang kedua atau selanjutnya anda harus dapat bergerak untuk megalihkan stres, misalnya dengan mendengarkan musik, mengajak anjing kesayangan berjalan keluar, pergi ke mal berbelanja atau ke pasar swalayan, melakukan rileks dengan berolah raga ringan. Yang ketiga anda harus melakukan hubungan dengan manusia, bisa teman karib, teman, atau saudara yang dapat mengerti diri anda dan membuat anda merasa aman dan menyenangkan, misalnya dengan cara menelpon teman lama, pergi jalan bersama, pergi makan siang atau berbincang di kedai minum, dan pergi makan malam bersama. Yang ke empat adalah melakukan waktu bersenang senang dan relaksasi, seperti melakukan hobi anda, melakukan apa yang anda senang lakukan setiap hari, misalnya bermain piano, pergi bersepeda, jogging, tetap menerapkan humor dan membuat anda tertawa, melakukan praktek relaksasi seperti yoga, meditasi, mencoba melatih pernafasan panjang, dan lain lain. Yang ke lima kelola waktu anda dengan lebih baik, seperti jangan terlalu menjanjikan sesuatu dikerjakan dalam waktu satu hari jika waktu yang tersedia terlalu sempit, buatlah suatu prioritas pekerjaan penting mana yang harus dilakukan terlebih dahulu, buatlah pekerjaaan besar menjadi hal yang semudah dan seefisien mungkin dikerjakan, delegasikan wewenang anda kepada orang yang dapat mengerjakan tugas tersebut, sebab tidak semua pekerjaan harus anda lakukan sendiri. Menurut Soewondo, S., Menaldi, A., Hanum, L. (2017), anda harus menjaga keseimbangan dengan gaya hidup yang sehat seperti makanlah yang bernutrisi tinggi dan sesuai serta tidak berlebihan, kurangilah asupan kafein dan makanan yang mengandung gula tinggi, sebab dengan mengurangi asupan ini anda akan mengurangi energi dan anda dapat lebih rileks dan mudah tidur, hindarilah merokok, minum alkhol dan minum drugs (sejenis narkoba), hal ini akan memberikan anda pikiran yang lebih tenang, bersih dan logika yang lebih bagus sehingga anda dapat memecahkan masalah secara lebih baik, dan tidurlah secara cukup, minimal 7 jam tidur malam dalam sehari. Menurut Mumpuni, Y., Wulandari, A. (2010), kita harus belajar untuk menghilangkan stress pada saat kita 
tertekan stres secara mendadak, misalnya ketika anda terjebak kemacetan dan lelah dengan perjalanan pagi anda ke kantor, terjebak dalam rapat yang membuat anda stres di tenpat kerja, atau karena pertengkaran dengan pasangan anda secara mendadak, maka cara tercepat untuk mengurangi stres adalah dengan menarik nafas dalam dalam, melihat foto favorit, mencium aroma tertentu, mendengarkan lagu favorit, mencicipi permen karet atau memeluk hewan kesayangan. Maka anda

\section{METODE PENELITIAN}

Metode pemberian stres manajemen kepada 85 orang karyawan tingkat manajer dan supervisor PT. Primus Pratama diberikan secara semiloka daring dengan melakukan presentasi dan tanya jawab antara peserta semiloka dan presenter Fahrul Riza pada tanggal 27 November 2020. Metode semiloka daring ini dipilih mengingat keadaan pandemi saat ini dan tidak memungkinkan bagi Universitas Bunda Mulia untuk melakukan pemberian materi stres manajemen secara tatap muka dengan para peserta pelatihan. Pada akhir presentasi juga diberikan kesempatan bagi para peserta pelatihan untuk bertanya kepada presenter dan presenter Fahrul Riza menjawab semua pertanyaan peserta pelatihan dengan sangat bagus, dan mendapatkan respon yang baik dari seluruh

\section{HASIL DAN PEMBAHASAN}

Hasil peserta pelatihan Stres Management (How To Turn Stess Into High Productivity ini mendapatkan respon yang sangat baik dan antusias dari para peserta pelatihan PT. Primus Prtama, yaitu para karyawan PT. Primus Pratama tingkat dapat dengan cepat rileks and memfokuskan diri.

Pengabdian kepada masyarakat ini kami berikan berupa semiloka kepada para manajer dan supervisor di PT. Primus Pratama, dengan maksud dan tujuan agar para manajer dan supervisor di PT. Primus Pratama dapat menanggulangi stress secara lebih baik dan memberikan hasil yang lebih produktif.

peserta pelatihan. Presenter Fahrul Riza juga memberikan contoh-contoh nyata dalam kehidupan yang ada hubungannya dengan stres, yaitu cara menghindari stres, cara menanggulangi stres, dan pemaparan mengenai hidup yang lebih tenang dan baik untuk mencapai hasil pekerjaan yang kinerjanya produktif. Selesai sesi pelatihan juga dibagikan kuesioner secara daring kepada para peserta pelatihan yang berisi pertanyaan mengenai kepuasan pelatihan, kepuasan hasil tanya jawab, dan usulan pelatihan serta umpan balik pelatihan. Hasil kepuasan pelatihan mendapatkan respon yang sangat baik dan antusias dari para peserta pelatihan.

manajer dan supervisor. Hasil tanya jawab juga mendapatkan respon yang sangat baik dari para peserta pelatihan dan hasil umpan balik peseta pelatihan dapat di lihat dari tabel di bawah ini: 
Tabel 1. Umpan Balik Peserta Pelatihan

\begin{tabular}{|c|c|c|c|c|c|c|c|c|c|}
\hline $\begin{array}{l}\text { Email } \\
\text { Address }\end{array}$ & Tema & $\begin{array}{l}\text { Nama } \\
\text { Instruktur/ } \\
\text { Narasumb } \\
\text { er }\end{array}$ & Tanggal & $\begin{array}{l}\text { Kema } \\
\text { mpua } \\
\mathrm{n} \text { atau } \\
\text { pengu } \\
\text { asaan } \\
\text { terhad } \\
\text { ap } \\
\text { materi }\end{array}$ & $\begin{array}{l}\text { Kema } \\
\text { mpua } \\
\mathrm{n} \\
\text { dalam } \\
\text { meny } \\
\text { ampai } \\
\text { kan } \\
\text { materi }\end{array}$ & $\begin{array}{l}\text { Kema } \\
\text { mpua } \\
\mathrm{n} \\
\text { meng } \\
\text { gunak } \\
\text { an } \\
\text { metod } \\
\mathrm{e} \\
\text { yang } \\
\text { tepat } \\
\text { denga } \\
\mathrm{n} \\
\text { materi }\end{array}$ & $\begin{array}{l}\text { Kema } \\
\text { mpuaan } \\
\text { dalam } \\
\text { menja } \\
\text { wab } \\
\text { pertany } \\
\text { aan } \\
\text { peserta }\end{array}$ & $\begin{array}{l}\text { Kema } \\
\text { mpua } \\
\mathrm{n} \\
\text { menci } \\
\text { ptaka } \\
\mathrm{n} \\
\text { suasa } \\
\text { na } \\
\text { yang } \\
\text { mend } \\
\text { ukung } \\
\text { kegiat } \\
\text { an }\end{array}$ & $\begin{array}{l}\text { Saran- } \\
\text { saran } \\
\text { perbai } \\
\text { kan } \\
\text { lainnya }\end{array}$ \\
\hline $\begin{array}{l}\text { palemba } \\
\text { ng.hm@ } \\
\text { cordelai } \\
\text { nn.com }\end{array}$ & $\begin{array}{l}\text { How } \\
\text { To } \\
\text { Turn } \\
\text { Stress } \\
\text { Into } \\
\text { High } \\
\text { Produ } \\
\text { ctivity }\end{array}$ & $\begin{array}{l}\text { Fahrul } \\
\text { Rizal }\end{array}$ & $\begin{array}{r}27-11- \\
20\end{array}$ & 4 & 4 & 4 & 4 & 4 & \\
\hline $\begin{array}{l}\text { sulistyo } \\
\text { danang } \\
07 @ g m \\
\text { ail.com }\end{array}$ & $\begin{array}{l}\text { Mema } \\
\text { nage } \\
\text { stress }\end{array}$ & Fadil Rozi & $\begin{array}{r}27-11- \\
20\end{array}$ & 3 & 3 & 3 & 3 & 3 & $\begin{array}{l}\text { Durasi } \\
\text { harus } \\
\text { ditamb } \\
\text { ah }\end{array}$ \\
\hline $\begin{array}{l}\text { charima } \\
\text { rgo@om } \\
\text { ega- } \\
\text { hm.com }\end{array}$ & $\begin{array}{l}\text { How } \\
\text { To } \\
\text { Turn } \\
\text { Stress } \\
\text { Into } \\
\text { High } \\
\text { Produ } \\
\text { ctivity }\end{array}$ & $\begin{array}{l}\text { DR. } \\
\text { Fahrul } \\
\text { Riza }\end{array}$ & $\begin{array}{r}27-11- \\
20\end{array}$ & 4 & 4 & 4 & 4 & 3 & \\
\hline $\begin{array}{l}\text { kuninga } \\
\text { n.fom@ } \\
\text { grandco } \\
\text { rdelahot } \\
\text { els.com }\end{array}$ & $\begin{array}{l}\text { Stress } \\
\text { Mana } \\
\text { geme } \\
\text { nt }\end{array}$ & $\begin{array}{l}\text { DR } \\
\text { Fakhrul } \\
\text { Rizal }\end{array}$ & $\begin{array}{r}27-11- \\
20\end{array}$ & 3 & 3 & 3 & 3 & 3 & \\
\hline $\begin{array}{l}\text { medan.c } \\
\text { imm.hrd } \\
\text { @cordel } \\
\text { a- } \\
\text { hotels.c } \\
\text { om }\end{array}$ & $\begin{array}{l}\text { STRE } \\
\text { SS } \\
\text { MANA } \\
\text { GEME } \\
\text { NT }\end{array}$ & $\begin{array}{l}\text { DR. } \\
\text { FAHRUL } \\
\text { RIZA SE., } \\
\text { MSM }\end{array}$ & $\begin{array}{r}27-11- \\
20\end{array}$ & 4 & 4 & 4 & 4 & 4 & $\begin{array}{l}\text { semua } \\
\text { baik } \\
\text { pak }\end{array}$ \\
\hline $\begin{array}{l}\text { posma.i } \\
\text { manuel } \\
\text { @gmail. } \\
\text { com }\end{array}$ & $\begin{array}{l}\text { How } \\
\text { To } \\
\text { Turn } \\
\text { Stress } \\
\text { Into } \\
\text { High } \\
\text { Produ } \\
\text { ctivity }\end{array}$ & $\begin{array}{l}\text { DR.Fahrul } \\
\text { Riza } \\
\text { SE.,MSM }\end{array}$ & $\begin{array}{r}27-11- \\
20\end{array}$ & 4 & 4 & 4 & 4 & 4 & $\begin{array}{l}\text { MANT } \\
\text { AP }\end{array}$ \\
\hline
\end{tabular}




\begin{tabular}{|c|c|c|c|c|c|c|c|c|c|}
\hline $\begin{array}{l}\text { itdev.co } \\
\text { ord@alf } \\
\text { aland- } \\
\text { group.c } \\
\text { om }\end{array}$ & $\begin{array}{l}\text { Stress } \\
\text { Mana } \\
\text { geme } \\
\text { nt }\end{array}$ & Dr Fahrul & $\begin{array}{r}27-11- \\
20\end{array}$ & 4 & 4 & 4 & 4 & 4 & $\begin{array}{l}\text { Terus } \\
\text { adaka } \\
\mathrm{n} \\
\text { acara2 } \\
\text { lain } \\
\text { lagi }\end{array}$ \\
\hline $\begin{array}{l}\text { rhendart } \\
\text { o@alfal } \\
\text { and- } \\
\text { group.c } \\
\text { om }\end{array}$ & $\begin{array}{l}\text { How } \\
\text { To } \\
\text { Turn } \\
\text { Stress } \\
\text { Into } \\
\text { High } \\
\text { Produ } \\
\text { ctivity }\end{array}$ & $\begin{array}{l}\text { DR.Fahrul } \\
\text { Riza } \\
\text { SE.,MSM }\end{array}$ & $\begin{array}{r}27-11- \\
20\end{array}$ & 4 & 3 & 3 & 4 & 4 & - \\
\hline $\begin{array}{l}\text { eharyati } \\
\text { @alfala } \\
\text { nd- } \\
\text { group.c } \\
\text { om }\end{array}$ & $\begin{array}{l}\text { How } \\
\text { To } \\
\text { Turn } \\
\text { Stress } \\
\text { Into } \\
\text { High } \\
\text { Produ } \\
\text { ctivity }\end{array}$ & $\begin{array}{l}\text { DR.Fahrul } \\
\text { Riza } \\
\text { SE.,MSM } \\
\text { (Dosen } \\
\text { PascaSarj } \\
\text { ana UBM) }\end{array}$ & $\begin{array}{r}27-11- \\
20 \\
\end{array}$ & 3 & 3 & 3 & 3 & 3 & $\begin{array}{l}\text { lebih } \\
\text { santai } \\
\text { lagi } \\
\text { sedikit } \\
\text { saja }\end{array}$ \\
\hline $\begin{array}{l}\text { ssumarg } \\
\text { o@yaho } \\
\text { o.co.id }\end{array}$ & $\begin{array}{l}\text { Stress } \\
\text { Mana } \\
\text { geme } \\
\text { nt }\end{array}$ & $\begin{array}{l}\text { DR. } \\
\text { Fahrul } \\
\text { Riza SE, } \\
\text { MSM }\end{array}$ & $\begin{array}{r}27-11- \\
20\end{array}$ & 4 & 4 & 4 & 4 & 4 & Cukup \\
\hline $\begin{array}{l}\text { wisnu.h } \\
\text { ousing } \\
\text { @alfala } \\
\text { nd- } \\
\text { group.c } \\
\text { om }\end{array}$ & $\begin{array}{l}\text { "How } \\
\text { To } \\
\text { Turn } \\
\text { Stress } \\
\text { Into } \\
\text { High } \\
\text { Produ } \\
\text { ctivity" }\end{array}$ & $\begin{array}{l}\text { DR.Fahrul } \\
\text { Riza } \\
\text { SE.,MSM } \\
\text { (Dosen } \\
\text { PascaSarj } \\
\text { ana UBM }\end{array}$ & $\begin{array}{r}27-11- \\
20\end{array}$ & 4 & 4 & 4 & 4 & 4 & \\
\hline $\begin{array}{l}\text { musting } \\
\text { ah@om } \\
\text { ega- } \\
\text { hm.com }\end{array}$ & $\begin{array}{l}\text { How } \\
\text { To } \\
\text { Turn } \\
\text { Stress } \\
\text { Into } \\
\text { High } \\
\text { Produ } \\
\text { ctivity }\end{array}$ & $\begin{array}{l}\text { Dr. Fahrul } \\
\text { Riza }\end{array}$ & $\begin{array}{r}27-11- \\
20\end{array}$ & 4 & 4 & 4 & 4 & 4 & $\begin{array}{l}\text { sangat } \\
\text { bagus }\end{array}$ \\
\hline $\begin{array}{l}\text { Evi.koes } \\
\text { wardani } \\
\text { @omeg } \\
\text { a- } \\
\text { hm.com }\end{array}$ & $\begin{array}{l}\text { STRE } \\
\text { SS } \\
\text { MANA } \\
\text { GEME } \\
\text { NT }\end{array}$ & $\begin{array}{l}\text { DR. } \\
\text { FAHRUL } \\
\text { RIZA }\end{array}$ & $\begin{array}{r}27-11- \\
20\end{array}$ & 4 & 4 & 4 & 4 & 4 & $\begin{array}{l}\text { semua } \\
\text { bagus }\end{array}$ \\
\hline $\begin{array}{l}\text { anurzairi } \\
\text { na@gm } \\
\text { ail.com }\end{array}$ & $\begin{array}{l}\text { Virtual } \\
\text { Learni } \\
\text { ng }\end{array}$ & $\begin{array}{l}\text { Pak } \\
\text { Fahrul }\end{array}$ & $\begin{array}{r}27-11- \\
20\end{array}$ & 3 & 3 & 3 & 3 & 3 & $\begin{array}{l}\text { Tdk } \\
\text { ada }\end{array}$ \\
\hline
\end{tabular}




\begin{tabular}{|c|c|c|c|c|c|c|c|c|c|}
\hline $\begin{array}{l}\text { paulus.i. } \\
\text { citrarah } \\
\text { ardi@alf } \\
\text { aland- } \\
\text { group.c } \\
\text { om }\end{array}$ & $\begin{array}{l}\text { How } \\
\text { To } \\
\text { Turn } \\
\text { Stress } \\
\text { Into } \\
\text { High } \\
\text { Produ } \\
\text { ctivity }\end{array}$ & $\begin{array}{l}\text { DR. } \\
\text { Fahrul } \\
\text { Riza SE, } \\
\text { MSM }\end{array}$ & $\begin{array}{r}27-11- \\
20\end{array}$ & 3 & 3 & 3 & 3 & 3 & - \\
\hline $\begin{array}{l}\text { mdn.ma } \\
\text { rketing } \\
@ \text { millen } \\
\text { nium- } \\
\text { ict.com }\end{array}$ & $\begin{array}{l}\text { Stress } \\
\text { Mana } \\
\text { geme } \\
\text { nt } \\
\text { (How } \\
\text { To } \\
\text { Turn } \\
\text { Stress } \\
\text { Into } \\
\text { High } \\
\text { Produ } \\
\text { ctivity) }\end{array}$ & $\begin{array}{l}\text { DR. } \\
\text { FAHRUL } \\
\text { RIZA SE., } \\
\text { MSM }\end{array}$ & $\begin{array}{r}27-11- \\
20\end{array}$ & 4 & 4 & 4 & 4 & 4 & $\begin{array}{l}\text { sudah } \\
\text { bagus } \\
\text { koq }\end{array}$ \\
\hline $\begin{array}{l}\text { gilangja } \\
\text { vanica } \\
\text { @gmail. } \\
\text { com }\end{array}$ & $\begin{array}{l}\text { HOW } \\
\text { TO } \\
\text { TURN } \\
\text { STRE } \\
\text { SS } \\
\text { INTO } \\
\text { HIGH } \\
\text { PROD } \\
\text { UCTI } \\
\text { VITY }\end{array}$ & $\begin{array}{l}\text { DR. } \\
\text { FAHRUL } \\
\text { RIZA SE., } \\
\text { MSM }\end{array}$ & $\begin{array}{r}27-11- \\
20\end{array}$ & 4 & 4 & 4 & 4 & 4 & \\
\hline $\begin{array}{l}\text { tjhinkoci } \\
\text { n@ome } \\
\text { ga- } \\
\text { hm.com }\end{array}$ & $\begin{array}{l}\text { How } \\
\text { to turn } \\
\text { stress } \\
\text { into } \\
\text { high } \\
\text { produ } \\
\text { ctivity }\end{array}$ & $\begin{array}{l}\text { Bpk. } \\
\text { Fahrul }\end{array}$ & $\begin{array}{r}27-11- \\
20\end{array}$ & 4 & 4 & 4 & 4 & 4 & \\
\hline $\begin{array}{l}\text { ho.pajak } \\
\text { @alfala } \\
\text { nd- } \\
\text { group.c } \\
\text { om }\end{array}$ & $\begin{array}{l}\text { How } \\
\text { To } \\
\text { Turn } \\
\text { Stress } \\
\text { Into } \\
\text { High } \\
\text { Produ } \\
\text { ctivity }\end{array}$ & $\begin{array}{l}\text { DR.Fahrul } \\
\text { Riza } \\
\text { SE.,MSM }\end{array}$ & $\begin{array}{r}27-11- \\
20\end{array}$ & 4 & 4 & 3 & 3 & 3 & \\
\hline $\begin{array}{l}\text { andrygu } \\
\text { nawan1 } \\
992 @ g \\
\text { mail.co } \\
\text { m }\end{array}$ & $\begin{array}{l}\text { Stress } \\
\text { Mana } \\
\text { geme } \\
\text { nt }\end{array}$ & $\begin{array}{l}\text { DR. } \\
\text { Fahrul } \\
\text { Riza SE, } \\
\text { MSM }\end{array}$ & $\begin{array}{r}27-11- \\
20\end{array}$ & 1 & 2 & 2 & 1 & 2 & \\
\hline $\begin{array}{l}\text { nanataw } \\
\text { wa@gm } \\
\text { ail.com }\end{array}$ & $\begin{array}{l}\text { Stress } \\
\text { Mana } \\
\text { geme } \\
\text { nt }\end{array}$ & $\begin{array}{l}\text { Pak } \\
\text { Fahrul. }\end{array}$ & $\begin{array}{r}27-11- \\
20\end{array}$ & 3 & 4 & 3 & 4 & 4 & $\begin{array}{l}\text { Cukup } \\
\text { puas } \\
\text { lah }\end{array}$ \\
\hline
\end{tabular}




\begin{tabular}{|c|c|c|c|c|c|c|c|c|c|}
\hline $\begin{array}{l}\text { jogja.hm } \\
\text { @cordel } \\
\text { a- } \\
\text { hotels.c } \\
\text { om }\end{array}$ & $\begin{array}{l}\text { How } \\
\text { To } \\
\text { Turn } \\
\text { Stress } \\
\text { Into } \\
\text { High } \\
\text { Produ } \\
\text { ctivity }\end{array}$ & $\begin{array}{l}\text { DR. } \\
\text { Fahrul } \\
\text { Riza SE., } \\
\text { MSM }\end{array}$ & $\begin{array}{r}27-11- \\
20\end{array}$ & 4 & 3 & 3 & 2 & 4 & t \\
\hline $\begin{array}{l}\text { HOTEL. } \\
\text { LANAN } \\
\text { G@GM } \\
\text { AlL.CO } \\
\text { M }\end{array}$ & $\begin{array}{l}\text { STRE } \\
\text { SS } \\
\text { MANA } \\
\text { GEME } \\
\text { NT }\end{array}$ & $\begin{array}{l}\text { DR. } \\
\text { FACHRUL }\end{array}$ & $\begin{array}{r}27-11- \\
20\end{array}$ & 4 & 4 & 4 & 4 & 4 & $\begin{array}{l}\text { KERE } \\
\mathrm{N}\end{array}$ \\
\hline $\begin{array}{l}\text { machruz } \\
\text { ar@mill } \\
\text { ennium- } \\
\text { ict.com }\end{array}$ & $\begin{array}{l}\text { how to } \\
\text { turn } \\
\text { stress } \\
\text { into } \\
\text { high } \\
\text { produ } \\
\text { ctivity }\end{array}$ & $\begin{array}{l}\text { fahrul } \\
\text { Riza }\end{array}$ & $\begin{array}{r}27-11- \\
20\end{array}$ & 4 & 4 & 4 & 4 & 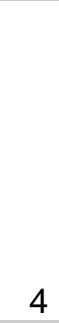 & $\begin{array}{l}\text { waktun } \\
\text { ya } \\
\text { yang } \\
\text { lebih } \\
\text { panjan } \\
\text { g } \\
\text { mungk } \\
\text { in }\end{array}$ \\
\hline $\begin{array}{l}\text { shinta.s } \\
\text { usilawati } \\
\text { @omeg } \\
\text { a- } \\
\text { hm.com }\end{array}$ & $\begin{array}{l}\text { How } \\
\text { to turn } \\
\text { stress } \\
\text { into } \\
\text { high } \\
\text { produ } \\
\text { ctivity }\end{array}$ & $\begin{array}{l}\text { Dr Fahrul } \\
\text { Riza SE } \\
\text { MSM }\end{array}$ & $\begin{array}{r}27-11- \\
20 \\
\end{array}$ & 3 & 3 & 2 & 3 & 3 & $\begin{array}{l}\text { Lebih } \\
\text { kepad } \\
\text { a } \\
\text { solusi } \\
\text { yang } \\
\text { banya } \\
\text { k krna } \\
\text { tingkat } \\
\text { stress } \\
\text { orang } \\
\text { yg } \\
\text { berbed } \\
\text { a } \\
\text { mengh } \\
\text { adapin } \\
\text { ya }\end{array}$ \\
\hline
\end{tabular}

\section{SIMPULAN}

Kesimpulan yang didapat dari para peserta pelatihan, yaitu para karyawan PT. Primus Pratama tingkat manajer dan supervisor adalah sebagai berikut:

1. Para karyawan PT. Primus Pratama merasa presentasi dengan topik
Stress Management (How To Turn Stress Into High Productivity) sangat bagus.

2. Para karyawan PT. Primus Pratama merasa sangat puas dengan hasil yang didapatkan dari pelatihan ini..

3. Para karyawan PT. Primus Pratama merasa topik yang dibawakan sangat menarik dan ingin mengulangi untuk 
mendapatkan topik yang sama pada kesempatan berikutnya.

4. Para karyawan PT. Primus Pratama merasa kemampuan atau penguasaan materi dan kemampuan dalam menyampaikan materi sudah sangat bagus dan berguna.

5. Para karyawan PT. Primus Pratama merasa habwa kemampuan

\section{DAFTAR PUSTAKA}

Cooper, C. L., Quick, J.C. (2017). The Handbook of Stress and Health: A Guide to Research and Practice, $1^{\text {st }}$ edition, John Wiley \& Sons Ltd.

Hawari, D. (2011). Manajemen Stres Cemas dan Depresi. Jakarta: Fakultas Kedokteran Universitas Indonesia menggunakan metode yang tepat dalam penyampaian materi sudah sangat bagus.

6. Para karyawan PT. Primus Pratama merasa bahwa kemampuan menciptakan suasana yang mendukung selama semiloka, saat pembawaan materi, dan saat tanya jawab sudah sangat bagus.

Mumpuni, Y., Wulandari, A. (2010). Cara Jitu Mengatasi Stres. Andi Publisher, Yogyakarta.

Saleh, M.L., Russeng, S.S., Tadjuddin, I. (2020). Manajemeen Stres Kerja (Sebuah Kajian Keselamatan Dan Kesehatan Kerja Dari Aspek Psikologis Pada ATC). Universitas Katolik Widya Mandira, Kupang.

Soewondo, S., Menaldi, A., Hanum, L. (2017). Stres, Manajemen Stres, dan Relaksasi Progresif. LPSP3 UI, Jakarta. 